\title{
Arte-educação online: formação continuada para professores de artes visuais ao uso das tecnologias contemporâneas no âmbito escolar
}

\section{Online Art-education: continued training for visual arts teachers about the use of contemporary technologies in the educational ambit}

\author{
Katyúscia Sosnowski [1] (PPGAV/UDESC)kaluhe@gmail.com
}

Márcia Suzana Caselgrandi Borges [2] (CINTED/UFRGS)masukaborges@gmail.com

\begin{abstract}
Abstrat: This text discusses the structure and real experiences of a workshop online, free, offered in January and February 2010 for visual arts teachers working in elementar education, through CEAD / UDESC, aiming to bring 40 teachers from 14 states in to country to the use of contemporary technologies in the context of art education. The workshop was based on constructivist principles, in proposing an effective participation of apprentices not only as an observer, but as a participant in the whole process. The modules containing: teaching art in virtual environments, virtual museums, multiculturalism, interdisciplinary projects in school. We considered the proposal and activities ending with consistent, quality projects.
\end{abstract}

Key words: Visual arts, contemporary technologie, Internet, distance education.

Resumo: Discorre-se neste texto a estrutura e a experiência vivenciada de uma oficina online, gratuita, oferecida entre janeiro e fevereiro de 2010, para professores de artes visuais atuantes no ensino fundamental formal, através do CEAD/UDESC, com objetivo de aproximar 40 professores de 14 estados do país ao uso de tecnologias contemporâneas no âmbito da arte-educação. A oficina esteve fundamentada nos princípios construtivistas, ao propormos uma participação efetiva dos aprendizes não apenas como observadores, mas como participante de todo processo. Entre os conteúdos: ensino de arte em ambientes virtuais, multiculturalismo, museus virtuais, projetos interdisciplinares na escola. Consideramos os projetos finais consistentes e de qualidade.

Palavras chaves: Artes visuais, tecnologias contemporâneas, Internet, formação continuada de professores a distância.

\section{Por que a educação à distância?}

As constantes transformações de ordem social, econômica, científica e tecnológica, acarretam o desenvolvimento e a qualificação profissional continuada de todo indivíduo e em todas as instâncias do conhecimento humano. Sabe-se que a realidade atual vem mostrando que as instituições educacionais não têm condições suficientes de atender a esta demanda, entretanto na EaD (Educação a Distância) podese encontrar uma alternativa que permite democratizar este processo educacional continuado e permanente. 
É evidente a expansão dos cursos de formação continuada de professores na rede de computadores, que vem se desenvolvendo consideravelmente. São várias as possibilidades oferecidas por instituições que primam pela inovação e acreditam na formação docente em cursos à distância.

\begin{abstract}
Considerando a elevação das exigências de formação de todos os professores da educação básica para o nível superior, determinada pela legislação nacional, grande esforço tem sido feito por parte de diferentes instâncias não só para preparar os novos profissionais que deverão prover as futuras necessidades do setor, como também para elevar o patamar de formação dos professores em serviço. (GATTI e BARRETO, 2009, p.35)
\end{abstract}

Numa perspectiva social, entendemos a EaD do mesmo modo que o ensino presencial, constituindo condição primeira de cidadania, dever essencial do Estado, política básica e obrigatória para ação de todo governo comprometido com uma educação de qualidade. No âmbito pedagógico, a EaD trás uma sustentação ao processo ensino-aprendizagem passando a ser um instrumento de qualificação, tamanho o potencial de utilização na capacitação e atualização dos profissionais como na formação e especialização em novas ocupações e profissões. A formação de professores de arte já faz parte deste cenário em parcerias com a Universidade Aberta do Brasil desde 2005 e com o plano nacional de formação de professores: a Plataforma Freire (2009), com propostas de Licenciaturas, especialização e formação continuada.

\begin{abstract}
Acredita-se que a ampliação de oportunidades proposta por meio da EaD, num processo qualificado colabora para a democratização do acesso a formação. O espaço virtual possibilita o uso de imagens virtuais de vários museus do mundo inteiro, bem como, o acesso a uma diversidade de produções artísticas de várias realidades. A modalidade de EaD se constitui como ferramenta que possibilita uma ampliação da formação de professores, não substituindo a educação presencial, nem a fruição dos objetos artísticos nos museus de arte. (ROSA, 2006, p. 2)
\end{abstract}

A EaD, como uma das modalidades de educação, precisa realizar-se como uma prática social significativa e conseqüente em relação aos princípios filosóficos de qualquer projeto pedagógico: a busca da autonomia, o respeito à liberdade e à razão. Entretanto, é fundamental que se tenha transparência sobre o uso da EaD como alternativa de democratização do ensino, pois sabemos que as questões educacionais não se resolvem pela aplicação técnica de um complexo sistema de comunicação. Vale lembrar Poleck (2002) [3], Superintendente da Educação a Distância e Continuada do Estado de Goiás, quando diz que "Não são as máquinas que integram. A integração maior vem das pessoas”.

Os processos de ensino-aprendizagem têm potencial para tornar-se mais ativos, dinâmicos e até mesmo personalizados por meio de Ambientes Virtuais de Aprendizagem (AVAs), pois esses agregam conteúdos e links além de armazenarem todo o material produzido pelos aprendizes, para que estes possam revisitá-los sempre que necessário. Essas mídias, em evolução, utilizam o ciberespaço para promover a aprendizagem, a interação e a colaboração a distância entre os atores do processo e o conteúdo a ser aprendido. Também, apresentam aspectos conceituais e bases legais com ferramentas que podem compor um AVA, assim como o material didático para a 
educação online. Nesses ambientes, a tecnologia é apenas um meio, pois a ênfase está na proposta, no conteúdo pedagógico e no desenvolvimento do processo educativo.

A escolha do AVA Moodle para a hospedagem da oficina "O uso de tecnologias contemporâneas no âmbito da arte educação” (2010) deu-se por este ser um open source composto de interfaces estratégicas programadas e que respeitam o ritmo de cada usuário. Os ambientes virtuais de aprendizagem envolvem desde a idéia, a organização, o armazenamento e as múltiplas formas de navegação e apropriação, assim como as múltiplas modalidades de criação, visualizando possibilidades outras não pensadas a priori. Porém, a qualidade do processo educativo depende do envolvimento do aprendiz, da proposta pedagógica, dos materiais veiculados, da estrutura e qualidade de professores, tutores, mediadores equipe técnica, assim como das ferramentas e recursos tecnológicos utilizados no ambiente.

\section{Planejamento da proposta de formação continuada para professores de Artes Visuais, online}

A proposta de uma oficina online, de formação continuada a distância, fora pensada para professores de arte que atuam nas séries finais do Ensino Fundamental formal, e que convivem com os adolescentes do século XXI, chamados por Prensky (2001) de nativos digitais. A oficina faz parte da pesquisa de mestrado em Artes Visuais, em andamento, de uma das autoras e teve como objetivo levantar dados e conhecer o perfil dos professores de arte atuantes em escolas públicas do país, as quais estão sendo beneficiadas com equipamentos de tecnologias de informação e comunicação, como também acesso a Internet por projetos como o E-Proinfo, e neste ano de 2010, o "Banda larga nas escolas" do governo federal. E também inserir professores de arte que acreditam na formação continuada a distância, como uma forma de inclusão aos que vivem longe de grandes centros e que encontram na Internet uma forma de participar de cursos de qualidade e pertinentes às necessidades da educação contemporânea.

Segundo Pimentel (2003), o professor de arte deverá viver e entender o que ocorre em arte e procurar acompanhar os avanços tecnológicos e avaliar como estas novas mídias pode auxiliar no ensino de artes visuais. "Imaginar as possibilidades artísticas via tecnologias contemporâneas é, também, estar presente no tempo em que vivemos".

Pensamos em uma experiência colaborativa e prática por entender que atividades como estas agregariam ao perfil dos professores que buscavam atualização, estes que em sua maioria tem uma carga horária semanal alta e pouco tempo para dedicar-se a textos acadêmicos. A oficina "O uso de tecnologias contemporâneas no âmbito da arte educação”, com carga horária de 40 horas, totalmente a distância fora organizada em módulos lineares, sendo o anterior pré-requisito ao subsequente. A divulgação foi feita via emails, lista de discussões e pelo site do Centro de Educação a Distância/CEAD-UDESC. As pré-inscrições foram recebidas por este site, acompanhadas de um questionário aberto a todos os candidatos, alcançando no prazo de 15 dias um número de 136 inscrições, vindas de 14 diferentes estados do país.

Consideramos, com o objetivo de selecionarmos os candidatos as 43 vagas oferecidas, nestes questionários, primeiramente, o segmento e local de atuação do professor/candidato, porque toda a oficina fora elaborada para professores que atuassem 
com estudantes dos anos finais do Ensino Fundamental de escolas formais públicas e gratuitas, com objetivo de aproximar esses professores. O segundo critério para seleção dos candidatos foi à localização geográfica, tínhamos como objetivos a inter-relação entre os mesmos em uma proposta de intercambio multicultural, entre regiões geograficamente distantes dentro do mesmo país. Ao final da análise dos questionários constatamos que $66 \%$ dos candidatos nunca haviam participado de um curso online, como também desconheciam a plataforma Moodle. Entre os candidatos tivemos um numero de $8 \%$ de professores de outras áreas e ou segmentos que realizaram a préinscrição.

Partindo de outras experiências em cursos de extensão, pensamos em uma equipe multidisciplinar de professores mediadores por entender que em um Ambiente Virtual de Aprendizagem somaríamos, trocaríamos e por fim aprenderíamos em comunhão. Para esta oficina convidamos quatro professores voluntários que tinham em seus currículos, ensino de arte, prática de ensino e experiência em educação a distância. Sendo os componentes: uma professora de arte, atuante nos últimos anos do Ensino Fundamental de uma escola pública do Rio Grande do Sul; uma professora, mestre em Educação, e licenciada em artes Visuais com experiência em tutoria online do estado de Minas Gerais; uma especialista em Educação a Distância do Rio Grande do Sul; e um pesquisador de ensino de arte, pela Internet, do estado de Goiás. A equipe de coordenadores compôs-se de uma professora licenciada em arte, mestranda do curso de artes visuais, especialista em arte educação e tecnologias contemporâneas, e de uma professora doutora do Centro de Educação a Distância e a equipe técnica tinha como base o CEAD-UDESC, o qual oferecia o suporte na plataforma virtual de aprendizagem Moodle. Contamos também com o apoio do grupo de pesquisa Arte Educação e Inclusão do CNPq.

Consideramos que a educação a distância necessita de diferentes pilares humanos e aproxima-nos como ressalta Freire:

... educar e educar-se, na prática da liberdade, é tarefa daqueles que sabem que pouco sabem - por isso sabem que sabem algo e podem assim chegar a saber mais - em diálogo com aqueles que, quase sempre, pensam que nada sabem, para que estes, transformando seu pensar que nada sabem em saber que pouco sabem, possam igualmente saber mais.(1986, p.25)

A equipe multidisciplinar, professores mediadores e coordenadores construíram colaborativamente, módulo a módulo a oficina, considerando como caminhos de aprendizagens a percorrer os quatro pilares da educação para o século 21, Ser, Conviver, Conhecer e Fazer, propostos no relatório para UNESCO por Jaques Delors (2003). De acordo com a aprendizagem proposta, a oficina apoiou-se na abordagem construtivista, a qual o tipo de acompanhamento e suporte ao participante se deu do início até o final da oficina pelos facilitadores (professores/mediadores), e a avaliação teve como base a interdependência das modalidades diagnóstica, formativa e somativa, com ênfase na sua continuidade. Em equipe e a distância, os professores configuraram a plataforma Moodle, planejaram via fórum de discussão e chats semanais discutiram sobre as estratégias e conteúdos abordados considerando a flexibilidade de rever o percurso a cada módulo levando em conta o público atendido. A experiência da equipe com EaD colaborou para o aprofundamento nas discussões e nas decisões das estratégias a serem acordadas.

\section{O Ambiente Virtual de Aprendizagem e os conteúdos abordados}


Aos poucos os participantes dos diferentes estados do país foram acessando e se ambientalizando ao AVA, a socialização foi imediata através do diálogo e as trocas entre pares à apropriação do espaço foi instaurada. Os primeiros contatos foram via email até que todos estivessem ambientalizados e logados na plataforma Moodle para interagirem com os colegas e professores mediadores.

Segundo Gutierrez e Prieto (1994), em um processo de educação a distância e alternativo, a forma de expressar o conteúdo deve ser organizada, acessível ao estudante e ilustrada. Além disso, é ao dar a forma ao conteúdo que o autor poderá utilizar recursos expressivos e de diagramação, tais como tipo de letras, de destaques, de cores, tipo de imagens. Para estes autores a mediação pedagógica ocorre "no tratamento de conteúdos e das formas de expressão dos diferentes temas, a fim de tornar possível o ato educativo dentro do horizonte de uma educação concebida como participação, criatividade, expressividade e relacionalidade.” (p.62)

A oficina foi organizada em cinco módulos, sendo o primeiro “Aprender a aprender a distância”, que teve como objetivo discutir o perfil do professor e do aprendiz que interage e aprende a distância, mediado por tecnologias de informação e comunicação (TIC’s). Concomitante com um primeiro contato com o universo digital, estava à proposta de uma atividade de edição de imagens com o tema Autorretrato, assim disponibilizamos tutoriais para o uso de alguns programas básicos como Photo Impression, Gimp e Paint. Neste módulo, percebeu-se o desafio para os professores em lidar com tecnologias e softwares, que os estudantes do ensino fundamental já dominam. Por meio de um fórum de discussão, que intitulamos "Dúvidas", todos participantes expuseram suas dificuldades, avanços e conquistas sobre a atividade, alguns atuaram como mediadores dos próprios colegas dando dicas sobre softwares mais complexos. O tema Autorretrato exigiu, além do conhecimento técnico, o desafio de trabalhar com a própria imagem, um olhar revisitado do eu "ser", quem sou? Como me significo? Os professores mediadores trouxeram contribuições de artistas e autores que tratam do assunto na contemporaneidade como os fotógrafos Vic Muniz e Margarida Medeiros. Os participantes anexaram imagens das cidades e da cultura local, ilustraram com poemas de sua autoria, exploraram e expandiram aspectos multiculturais. Destacamos a mensagem postada no fórum de discussão de um dos participantes do estado do Espírito Santo:

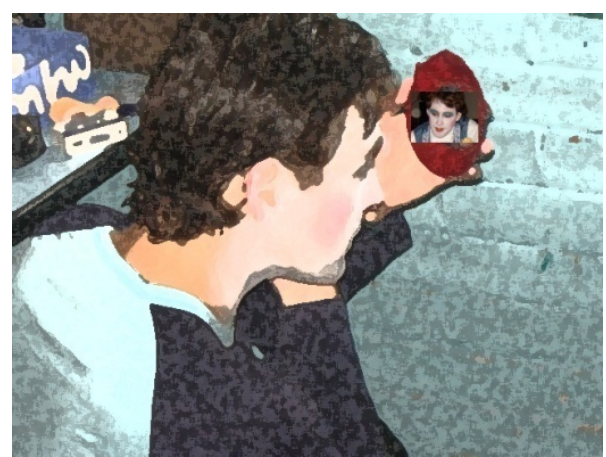

Figura1 - Autorretrato publicado no AVA

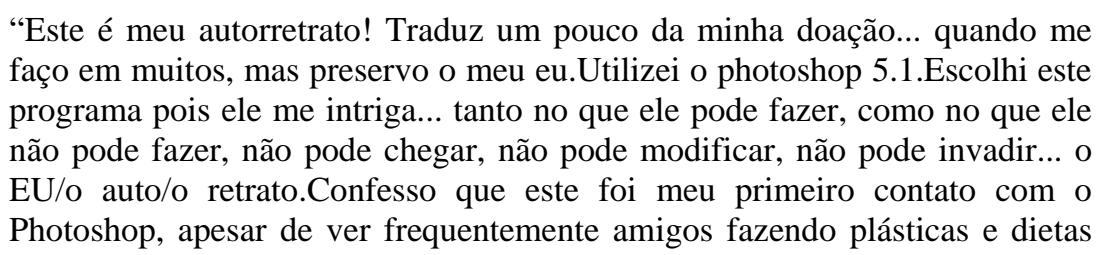


virtuais com emagrecimento instantâneo...Na construção de um autorretrato o Photoshop pode te auxiliar no revelar novos EUs ou escondê-los, afinal este programa vem sendo usado constantemente para esconder o que a sociedade considera fora dos padrões. Mas ele me ajudou a revelar! É uma ótima fonte de reflexão junto aos alunos. O autorretrato sempre está presente no meu trabalho em arte-educação, mas nunca utilizei com meus alunos TICs, e este foi o primeiro passo! T.Z. Vitória/ES” (2010)

A edição das imagens foi um desafio como consta no registro acima feito por um dos professores participantes da oficina, mas também uma motivação, e as dificuldades sobre formatação e edição das imagens foram discutidas e exploradas exaustivamente no fórum “Dúvidas”.

No segundo módulo, “O ensino de arte na contemporaneidade e as relações com a arte contemporânea e a tecnologia”, propomos leituras teóricas e discussões em grupos menores acompanhados pelos professores mediadores. Propomos e disponibilizamos no AVA,textos sobre o ensino de arte na contemporaneidade, como também relacionados à Arte contemporânea e o uso de novas tecnologias no âmbito escolar, tendo em vista a ausência destas temáticas no ensino da arte na atualidade. Discutimos conceitos da arte contemporânea a partir do vídeo "O que é arte contemporânea?", produzido pelo Projeto "Rumos” do Itaú Cultural, anexado no ambiente virtual. Este promoveu diversas discussões e também ampliou o conhecimento sobre o tema, segundo textos publicados por muitos dos participantes. Fundamentados em Fahy (2004), podemos dizer que os recursos digitais e impressos adequados para um AVA devem ser cuidadosamente planejados pela equipe do projeto considerando seu público-alvo.

No terceiro módulo, "Possibilidades de ensino e aprendizagem a distância em ambiente virtuais", os participantes exploraram, criaram e discutiram as possibilidades pedagógicas sobre o uso de blogs, AVAs, redes sociais e sites de museus virtuais como possíveis ambientes virtuais de aprendizagem. Para finalizar este módulo os participantes produziram uma lista dos museus virtuais, visitados e considerados por eles interessantes para utilizar nas aulas de arte com estudantes do ensino fundamental.

No quarto módulo, “Trocas multiculturais entre realidades distantes geograficamente”, os grupos foram organizados pelos professores mediadores que consideraram características como assiduidade, pontualidade e localização geográfica. Neste módulo os participantes conheceram um projeto piloto de ensino de arte a distância, aplicado em escolas das cidades de Itapema/SC, Canoas/RS e Florianópolis/SC, com 112 estudantes de oitava série juntamente com suas professoras de arte em uma plataforma Moodle. Outra atividade deste módulo foi uma vídeoconferência sobre multiculturalismo no ensino de arte ministrada por uma das coordenadoras por meio da ferramenta Meeting, da Adobe ConnectNow, diretamente do CEAD/UDESC com a participação de 14 professores online. Os relatos de experiência e os projetos finais elaborados no último módulo pelos professores de arte participantes merecem destaque por acreditarmos que nestas atividades os mesmos se envolveram e demonstraram um perfil reflexivo e pesquisador.

\section{Relatos de experiências}

Uma das atividades do segundo módulo da oficina foi uma proposta de envio de um relato de experiência individual, vivenciado em sala de aula, poderia ser um projeto ou mesmo uma aula que envolvesse a temática da arte contemporânea. O AVA 
Moodle registrou 27 arquivos enviados dos 43 professores de arte participantes do curso. Analisando os conteúdos dos relatos, apenas seis traziam experiências significativas sobre as temáticas da arte contemporânea na sala de aula, conteúdos como vídeoart, arte instalação, body art, apareceram nos relatos. É percebido que o conteúdo sobre arte contemporânea ainda aparece tímido nos planejamentos escolares. Wilson (2005) destaca que:

Embora a arte educação seja apenas uma pequena parte do mundo da arte - e aos olhos de muitos, uma parte insignificante - ela é, apesar disso formada e modelada pelo mundo da arte, e reflete suas crenças. A arte educação tem muitos valores em comum com o mundo da arte, os professores reproduzem as mesmas concepções de realidade que são encontradas também no mundo da arte. (p.83).

O autor aponta para um diálogo entre as praticas artísticas e a educação em arte, porém o que encontramos ainda são crenças modernistas não apenas nesta amostra, mas em grande parte dos arte - educadores no Brasil ,um distanciamento entre a arte contemporânea e o ensino de arte nas escolas já apontado por Menezes (2007, p.11) que aborda essa problemática "muitos professores não deixam de vivenciar um estranhamento similar ao que grande parte das pessoas tem em relação à arte contemporânea e assim ao justificarem-se por não entender a arte contemporânea a excluem de seus programas e planos de aula”.

Acreditamos que o contato durante a oficina com textos que abordaram a temática da vídeoart na escola, como também o ensino da arte contemporânea nas escolas, contribuiu para uma desmistificação do tema por parte dos professores que após uma discussão aberta puderam refletir sobre o estranhamento causado muitas vezes pela falta de contato e conhecimento do público com a obra de arte contemporânea.

\section{Projetos finais}

Entre os projetos propostos como atividade final da oficina, merecem destaque os aspectos sobre uma educação multicultural e inclusiva, que leva em conta o vínculo com a realidade social, o entorno e a prima pelo incentivo à entrada da comunidade na escola, como ressalta Rosa (2004, p.41)

\footnotetext{
"Propondo a inclusão de temas importantes, do contexto dos alunos na pauta das atividades escolares, os professores estarão resguardando a estes alunos, espaço para diferenciar-se da cultura oficial. Desta forma a escola colabora para o resgate cultural de muitos grupos oprimidos e partilha do processo de construção de uma escola inclusiva”.
}

O multiculturalismo proposto por Peter McLaren, estudioso de Paulo Freire permeou nossas concepções pedagógicas neste último módulo, no qual partilhamos dos pressupostos multiculturais críticos para a elaboração dos projetos. Desde a organização dos grupos pelos professores mediadores que consideraram a localização geográfica dos integrantes objetivando a diversidade cultural, como também na proposta de seguir o projeto por cinco eixos norteadores. O projeto tinha como foco de aplicação as escolas básicas em especial os alunos das séries finais do ensino fundamental. Paralelo a isso os participantes criaram um blog para registrar a arte local e regional de seus estados e cidades, disponível no endereço: http://ticsarte.blogspot.com

Elaborados nos fóruns de discussão, colaborativamente por oito participantes de diferentes estados do país, auxiliados pelos professores mediadores, os projetos 
tinham em sua essência a multiculturalidade quando abordaram artistas sem renome internacional, destacando artistas locais e regionais. Após elegerem quais seriam as escolas dentro de cada grupo que poderiam acolher o projeto, o grupo investigou se estas possuíam laboratório de informática com Internet e no currículo duas aulas semanais de arte, podendo incluir visitas regulares ao laboratório de informática como também eventuais visitas a espaços expositivos. Definidas as escolas/cidades os quatro grupos juntamente com os participantes representantes dessas, elegeram um artista contemporâneo que tivesse representividade na cidade ou região. As oito escolas definidas pelos professores foram consideradas equipadas tecnologicamente para receberem o projeto, localizadas em: Sergipe/ES, São José dos Pinhais/PR, Resende/RJ, Santa Catarina/SC, São Leopoldo/RS, Tanabi/ SP, Caxias do Sul/RS, Natal/RN, e os artistas propostos pelos mesmos foram Adriana Varejão, Bispo do Rosário, Eduardo Wolf de Oliveira, Walter Firmo, Iberê Camargo, Rogério Medeiros, Ivens Machado e Os Gêmeos.

\title{
Avaliações do percurso
}

Entendemos que a avaliação constitui-se imprescindível e indispensável no esforço de levantamento das dificuldades específicas de cada aprendiz e na busca da autonomia para que cada um deles trilhe com sucesso o caminho da aprendizagem. Portanto, ela deve ser um processo contínuo e progressivo, sendo que é através do diagnóstico que daremos continuidade à construção de novas fases no processo de ensino aprendizagem, e, para tanto, necessita ser planejada, executada e avaliada. Neste sentido, ela assume uma dimensão orientadora como afirma Luckesi:

\begin{abstract}
"No que se refere às funções da avaliação da aprendizagem, importa ter presente que ela permite o julgamento e a conseqüente classificação, mas essa não é a sua função constitutiva. É importante estar atento à sua função ontológica (constitutiva), que é de diagnostico, e, por isso mesmo, a avaliação cria a base para a tomada de decisão, que é o meio de encaminhar os atos subseqüentes, na perspectiva de busca de maior satisfatoriedade nos resultados”. (Luckesi 2003, p. 176).
\end{abstract}

Em vista disto, para a avaliação do processo ensino aprendizagem nos apoiamos nas categorias funcionais descritas por Benjamin Bloom (1956): diagnóstica (analítica), formativa (controladora) e somativa (classificatória).

Visando identificar a realidade dos participantes e verificar se eles apresentavam ou não habilidades e/ou pré-requisitos para o processo foi proposto um questionário pré-seletivo cujas questões versavam sobre conhecimentos prévios das temáticas da oficina, e também sobre a disponibilidade e comprometimento com um ensino na modalidade a distância, assim como sobre o cotidiano escolar, o que nos serviu para selecionar os 43 participantes para preencherem as vagas oferecidas. Durante o processo ensino aprendizagem, os professores/mediadores se reuniam uma vez por semana, na sala de Chat, para identificar problemas ou dificuldades recorrentes na aprendizagem, para então propor aos aprendizes uma revisão de suas ações educativas.

Com o intuito de promover a aprendizagem, no sentido de harmonizar, tranquilizar, apoiar, orientar, reforçar, corrigir, etc., oferecíamos feedback constantes, assim como, através da ferramenta “Diário" mantínhamos diálogos individualizados que permitiam ao aprendiz analisar situações, reconhecer e corrigir seus eventuais erros nas 
atividades propostas, sob a forma de elogios e estímulos. Para a avaliação do processo, nos servimos de quatro parâmetros: questionário de autoavaliação, planilha dos objetivos previstos, avaliação individual dos mediadores responsáveis e questionário de avaliação dos cursistas sobre a oficina. Este último item nos permitiu uma reavaliação de todo o processo. Sob a avaliação dos participantes, a oficina foi considerada, com qualidade significativa, quanto aos seus conteúdos programáticos, metodologia, acompanhamento e processo ensino-aprendizagem, no seu todo. A avaliação da oficina, pensada em seu conjunto, denota um significativo grau de satisfação, compromisso e seriedade, por parte dos aprendizes, sobre a forma como a mesma foi desenvolvida e sobre suas contribuições teórico-práticas para o enriquecimento profissional dos participantes. Acreditamos que essas formas de avaliação foram conjugadas e garantiram a eficiência do sistema de avaliação e a excelência do processo ensinoaprendizagem.

Evidenciamos que, dentre os 43 participantes, 13 desistiram durante o processo, 06 não atingiram os $75 \%$ para a certificação e 24 concluíram a oficina com mérito. Concluímos que o percentual de 56\% de certificação para a modalidade de ensino a distância, em época de recesso escolar, sendo que a maioria nunca tinha participado de um curso online e desconheciam o Ambiente Virtual de Aprendizagem Moodle é relevante e satisfatório.

\section{Considerações}

É importante ressaltar que a formação dos professores é uma necessidade constante, e ressituar as funções dos professores aproveitando suas experiências e a necessidade de se adotar novas posturas pedagógicas adequadas às rápidas transformações do mundo digital torna-se imprescindível. È necessário que professores de arte, em especial os de artes visuais, estejam dispostos a se preparar para uma nova proposta que visa mudanças e inovações, essas que irão ampliar seu repertório tanto imagético como pedagógico. Faz-se indispensável o desenvolvimento do professor e uma aproximação dele com as tecnologias contemporâneas com investimentos contínuos na construção e reconstrução de seu saber pedagógico e tecnológico. A educação a distancia mediada por TIC's se apresenta como uma opção àqueles que desejam ampliar seus conhecimentos e não dispõem de tempo ou mesmo estão distantes de instituições que ofereçam cursos de qualidade. Mediante as propostas de formação de professores, oferecidas pelo Governo Federal nos últimos anos, as ofertas se ampliam e as fiscalizações também, trazendo mais qualidade e acesso à educação. Sendo que os estudantes do século XXI encontram todas as respostas em sites de busca na rede mundial de computadores, é preciso então, que os professores aprendam a elaborar e refletir sobre como serão as perguntas a partir de agora. Estamos vivenciando a transição na educação para a era digital e é preciso re-formar os professores para conviver com os estudantes nativos digitais. Não há como ignorar esse conhecimento dentro da escola atual.

Percebeu-se, através das discussões levantadas sobre arte contemporânea, que muitos professores de arte partilham do mesmo estranhamento sobre ela como os leigos, e nos relatos de experiências enviados pelos participantes as temáticas da arte contemporânea aparecem em números muito baixos, sinalizando questões sobre a formação dos professores para este conteúdo. 
Constatou-se, através dos projetos elaborados pelos participantes da oficina, que os artistas escolhidos localizam-se fora do eixo eurocêntrico e que a integração entre pares distantes geograficamente foi ultrapassada pelo parentesco intelectual já anunciado por Freire. A interação, no que tange ao diálogo e comprometimento com as atividades em grupo, foi comprovada nesta experiência, na qual os participantes apesar de separados geograficamente, estavam muito próximos virtualmente e com um objetivo em comum, aprender para ensinar. Também, que a multiculturalidade proposta por Peter McLaren, permeada nos projetos, permitiu novos olhares sobre a cultura local e regional contemporânea, abrindo caminhos para uma aproximação da arte na contemporaneidade por parte dos professores e conseqüentemente seus alunos.

Os dados registrados do alto número de inscrições, num curto espaço de tempo apontam para a demanda do mercado para este tipo de oficina, oferecida em período de férias escolares, totalmente a distância e gratuita para professores de arte. Acreditamos que os dados levantados, como também as possibilidades de projetos elaborados pelos participantes nesta experiência muito contribuirão para a pesquisa de mestrado em Artes Visuais da autora, assim como em novas pesquisas sobre a temática. A qualidade do curso/oficina, relatada pelos participantes na avaliação final, nos faz acreditar que, uma educação continuada totalmente a distância pode alcançar grandes conquistas.

[1] Bolsista CAPES, mestranda, aluna regular do curso de Pós-graduação em Artes Visuais da UDESC.

[2] Pós-graduanda em Informática na Educação/UFRGS;

[3] http://penta3.ufrgs.br/videos/tvescola/integracaomidias128.html, vídeo assistido em 15.03.07.

\section{Referências bibliográficas:}

BELLONI, M. L. O que é mídia-educação. 2ªed. Campinas, SP: Autores Associados, 2005.

BLOOM, Benjamin et al. Taxonomy of Educational objectives. Hand Book I, Nova Iorque, 1956.

COHN, Greice. A Pedagogia transformadora da arte contemporânea, caderno de textos. Diálogos entre Arte e público. $2^{\mathrm{a} e d}$ Rio de Janeiro, 2009.

DELORS, J. Os 4 pilares da Educação in. Educação: um tesouro a descobrir. Brasília, DF: MEC/UNESCO, $2^{\text {a}}$ ed. São Paulo: Cortez, 2003. Disponível em:

http://www.ia.ufrrj.br/ppgea/conteudo/T1SF/Sandra/Os-quatro-pilares-da-educacao.pdf acesso em 09 dez 2009.

FAHY, Patrick J. Media characteristics and online learning technology. 2004. In: TerryANDERSON, T. e ELIOUMI, F. Theory and Practice of Online Learning. Athabasca: cde.athabascau.ca/online_book, 2004, 421p.

FERNANDES, S. M. FONSECA da SILVA, R.C.M, SOSNOWSKI, K. O uso de ambientes virtuais de aprendizagem para o ensino de arte, grupo Marron,19 ConFaeb,Belo horizonte. 2009. 
FREIRE, P. Extensão ou comunicação? 7ªd. Rio de Janeiro: Paz e Terra, 1986.

GATTI, Bernardete; BARRETTO, Elba S. de Sá. Professores no Brasil: Impasses e desafios. Brasília: Unesco, 2009. Disponível em: http://www.brasilia.unesco.org/publicacoes/livros/professores-do-brasil acesso em 24 abr 2010.

GUTIERREZ, Francisco; PRIETO, Daniel. A mediação pedagógica: a educação a distância alternativa. São Paulo: Papirus, 1994.

LUCKESI, Cipriano Carlos. Avaliação da aprendizagem escolar: estudos e preposições. 15a ed. São Paulo: Cortez, 2003.

MCLAREN, Peter. Multiculturalismo Crítico. 3aed. São Paulo: Cortez, 2000.

MENEZES, Marina Pereira de. A arte contemporânea como conteúdo e fundamento para a prática do ensino de artes. Rio de Janeiro, 2007. Universidade do Estado do Rio de Janeiro. Dissertação de Mestrado.

PELLANDA, M.Campos, Nize. Inclusão Digital, tecendo redes afetivas /cognitivas. Rio de Janeiro: Editora DP\&A, 2005.

PRENSKY, M. 2006. Don't Bother Me Mom - I'm learning!. Paragon House, Minnesota. Disponível em:

www.senacnet.com.br/arquivos/arquivo20080709111520texto-pedro-demo--extrato-

finaldoc.doc , acesso em 01 de jun 2010.

PIMENTEL, Lúcia. Tecnologias Contemporâneas e o Ensino da Arte. IN: BARBOSA, Ana Mae. (org). Inquietações e Mudanças no Ensino da Arte. São Paulo: Cortez, 2003.

ROSA, Maria Cristina. A educação de professoras e professores de arte: construindo uma proposta de ensino multicultural à distância. Universidade Federal de Santa Catarina, Florianópolis, p.187, 2004. Tese de Doutorado.

A Formação de professores de arte: diversidade e complexidade pedagógica. Florianópolis: Insular, 2005.

A educação inclusiva de professores de arte a distância: possibilidades e conflitos. Revista Educação: volume 31, n² 2, 2006. Disponível em: http://coralx.ufsm.br/revce/revce/2006/02/a9.htm , acesso em 2 de junho de 2010.

WILSON, Brent. Mudando conceitos da criação artística: 500 anos de arte educação para crianças, in BARBOSA ANA MAE, (org). Arte/Educação contemporânea - Consonâncias internacionais. São Paulo: Cortez, 2005. 